\title{
A Time Series Analysis of Household Income Inequality in Brazil From 1977 to 2013
}

\author{
Marcel Caparoz ${ }^{*}$ \\ EMERSON FERnandes MarÇal ${ }^{\dagger}$ \\ EnLINSON MATtos
}

\section{Contents}

1. Introduction

2. Motivation.

3. Dataset and Econometric

Methodology

4. Results

5. Conclusion

Keywords

Income inequality evolution,

time-series analysis, public policies

JEL Codes

$\mathrm{J} 50, \mathrm{~J} 30$

\section{A Abstract $\cdot$ Resumo}

This study analyzes the evolution of household income inequality in Brazil from 1977 to 2013. Four quantiles are analyzed: Top 1\%, Top $10 \%$, Bottom $10 \%$, and Bottom $50 \%$. The novelty of our study lies in the use of time-series techniques to understand the phenomenon of income inequality. We use the Markov-switching regime change and state-space structural time series techniques. Both strategies suggest that income concentration periods in Brazil are related to low growth rates but high inflation rates. Recent inequality reduction in the shares of the Top $1 \%$ quantile can be viewed as a "back to normal" transition.

\section{Introduction}

In the last few decades, income inequality has shown a rising trend in some developed countries such as the United States, Germany, and Japan. Since the work of Kuznets and Jenks (1953), many authors have documented the evolution of income and wealth in many developed economies (Lampman, 1962; Atkinson, 2005; Piketty, 2003; Atkinson \& Piketty, 2010; Alvaredo, Atkinson, Piketty, \& Saez, 2013; Piketty \& Saez, 2014; Piketty \& Saez, 2014; Soltow, 1991; Piketty, 2010).

Meanwhile, Brazil experienced an opposite trend with a persistent decline in inequality during this period. Although this income inequality trend is documented at the aggregate level, the literature is silent on the patterns of income concentration in different income brackets at the regional level. A better understanding of these differences is important not only to formulate policy but also to unveil issues that cannot be addressed by only looking at aggregate data. The debate on income inequality in

\footnotetext{
${ }^{*}$ Economist at RC Consultores. Rua James Joule, 92, $10^{\circ}$ andar, São Paulo, SP, CEP 04576-080, Brazil. (10 0000-0002-6328-3592

${ }^{\dagger}$ Fundação Getulio Vargas, Escola de Economia de São Paulo (FGV/EESP), Centro de Estudos em Macroeconomia Aplicada. Rua Itapeva, 286, $10^{\circ}$ andar, São Paulo, SP, CEP 01332-000, Brazil. (1) 0000-0002-0841-5644

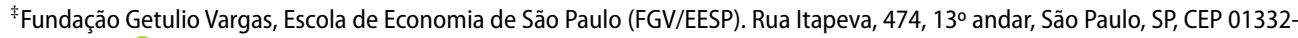
000, Brazil. 0000-0001-7351-1280

$\square$ marcel.caparoz@gmail.com $\square$ vitorozaki@hotmail.com $\square$ enlinson.mattos@fgv.br
} 
Brazil has grown in the last decade, mainly because of changes in the economic, political, and social environment over the past 40 years. In the 1970s, the Brazilian economy faced a period of economic prosperity with many people evolving to middle-class standards. The second-round increase in oil prices in the late 1970s had a decisively negative impact on Brazilian growth. In the 1980s, the Brazilian economy faced an economic downturn, hyperinflation, and bailouts. ${ }^{1}$ Analysts call this period the "lost decade." The pattern of income distribution was drastically affected by the economic environment in all regions and social levels.

In the 1990s, Brazilian officials managed to stabilize macroeconomic indicators by adopting reforms that led to inflation reduction and moderate growth. Macroeconomic stabilization helped recover the purchasing power and income of individuals and households. The poorest ones were not able to protect themselves against the deleterious effects of inflation on their income and wealth; hence, these effects were particularly important to them. The twenty-first century began with a boom in commodities prices, and Brazil is a great exporter of many commodities such as soybean, coffee, and iron ore. The Brazilian federal government also launched many programs that aimed to reduce poverty by using direct income transfers.

This paper aims to construct and analyze the patterns of income distribution for Brazil (and its regions) in different quantiles. The period of our sample is from 1977 to 2013. Time series are constructed with income concentration for four income brackets (Top 1\%, Top 10\%, Bottom 10\%, and Bottom 50\%) for Brazil and its five regions using the National Household Sample Survey (PNAD), collected by the Brazilian Institute of Geography and Statistics (IBGE). ${ }^{2}$ We investigated the existence of different regimes in those series by using rigorous and modern time-series techniques. Two methodologies are used: (i) a Markov-switching methodology developed by Hamilton (1989) and (ii) structural time series techniques developed by Harvey (1990).

Our results detect a new regime of high-income shares in the poorest quantiles for aggregated data and some regional data in the 2000s, suggesting an improvement in income distribution for those individuals. For the Top 1\% quantile, a regime of high-income shares had prevailed during the 1980s and 1990s. Recently, we find a change in the regime of the low-income shares similar to the one prevailing at the beginning of our sample period, which suggests that the contribution of these quantiles to reducing inequality can be viewed as a "back to normal" transition instead of as the beginning of "a new era." Our second strategy, state-space models, also suggests that the macroeconomics of the 1980s had severe effects on Brazilian inequality, whereas the dynamics of the Top $1 \%$ income share reinforce the return to previous stages of income concentration. Our strategy reveals another phenomenon that might explain income concentration: high levels of inflation. This result contrasts most of the empirical literature for developed countries that argues that growth is the main reason for income concentration. It is noteworthy that our estimates unveil important regional differences in many quantiles, mainly in the bottom brackets whereby inequality seems to decrease more gradually in poorer regions compared with the richer regions in Brazil.

\footnotetext{
${ }^{1}$ Cline (1995) reviews Latin America debt crisis events dealing with the Brazilian debt crisis.

${ }^{2}$ Unfortunately, this survey does not allow us to build a time series of wealth inequality in Brazil.
} 
This paper is organized in five sections including this introduction. In section 2, a literature review on income inequality in Brazil is presented. In section 3, a dataset is shown, and the econometric methodology is discussed. In section 4, the results of two econometric exercises are reported and discussed. Finally, some final remarks are discussed.

\section{Motivation}

Many factors can affect the dynamics of income inequality. Brazil has many distinct features over the recent past that make it an interesting subject for income distribution studies. In the 1970s and 1980s, Brazil experienced chronic inflation. Particularly in the 1980s, Brazil suffered from macroeconomic imbalances, an unprecedented level of inflation (even by Brazilian standards), public deficits, and bailouts. From 1994 to 2010, Brazil faced a period of unprecedented macroeconomic stability and a rapid demographic transition. During the 2000s, a policy of direct income transfers to the poor was launched, and important changes in the labor market also occurred. To unveil these trends and determine when these aforementioned factors positively or negatively affect income inequality, a rigorous investigation of time trends in Brazilian data is essential. In particular, how the richest and poorest households were affected by these trends needs to be explored.

\subsection{Why is using a time-series approach important in dealing with income-inequality data?}

Data on income inequality over a long period are available for many countries. Although it is important to understand the factors driving the changes of income inequality from two points in time for one country, determining new trends and structural change using data from one country and common trends among countries, regions, or income share quantiles is also important to obtain a comprehensive view of the phenomenon. Since the 1980s, a revolution in time-series techniques has allowed analysts to analyze non-stationary data and detect changes in trends and structural change. ${ }^{3}$

Time-series techniques have been used to address possible income inequality trends many times in the literature. One of the first studies is that of Blinder and Esaki (1978). They used time-series data and tried to assess the importance of unemployment and inflation on income inequality. In their regressions, the hypotheses of the existence of a time trend and structural change were also investigated. Although their results may be challenged using recent advances in the time series field, they found evidence in favour of the hypothesis that unemployment causes a negative and significant impact on income inequality but not inflation. If inflation had any impact, it would be a positive one.

Another possible approach to deal with income inequality using Time-series data is to investigate the time-series properties using univariate analysis without explanatory variables. This is the approach used in our paper. Raj and Slottje (1994) opted for univariate analyses. They ran the test of Zivot and Andrews (1992) to investigate the existence of a unit root, a possible (broken) time trend in the data of income inequality. They investigated different measures of income inequality and claimed that the series

\footnotetext{
${ }^{3}$ Maddala and Kim (1998), and Pesaran (2015) provide a rigorous discussion of these developments.
} 
is better described as a stationary process around a broken trend compared with the first-difference stationary process. The period investigated by the authors is from 1947 to 1990 for the United States. Their results suggest that a break in the trend occurred around 1965. After that point, a positive trend in inequality could be detected.

The unit root tests exhibit a well-known power problem if the data-generating process contains a high level of persistence. A longer time series is required to circumvent this problem. Roine and Waldenström (2011) work with a secular and comparable dataset for a group of developed countries. They use data that covers the Great Depression in the 1930s, Second World War, and Post-War period. The longest series starts in 1900 and ends in 2005 for Japan. They use the method developed by Bai and Perron (1998, 2003) to investigate the existence of multiple changes in the data-generating process. Particularly, they are interested in investigating the existence and possible structural changes in time trends. Their study does not focus only on aggregated data but also on the analysis of the time evolution of different quantiles, similar to our approach. They also investigated whether countries share the same trends. They were able to find a new upward trend around the 1960s and 1970s for Anglo-Saxon countries.

\subsection{Background on Brazilian income inequality}

The dynamics of income inequality have gained attention recently because of the rising inequality that has been observed in developed countries. After the Great Depression, a falling trend in income inequality had been observed globally throughout the following decades until the 1970s. In the 1980s, a rising trend was observed again, and the level of income inequality at present is equivalent to that of the 1929 pre-crisis period. Piketty and Saez (2006) highlight that this trend is not restricted to the United States. Other developed countries such as Canada and the United Kingdom demonstrate a similar pattern. France seems to be an exception. Since after the fall in the 1940s, income inequality has been virtually stable. Tachibanaki (2006) report a similar pattern for Japan.

Atkinson and Piketty (2007) studied the income inequality pattern for continental Europe and native English-speaking countries during the twentieth century. Alvaredo et al. (2013) expanded the analysis to 22 countries from Asia, Europe, Oceania, North America, and South America. Piketty (2014) states that the growing income inequality after the 1980s was due to the increase in the share of labor income, which is in contrast to what happened in the 1929 pre-crisis period when inequality was largely due to capital income, such as profits, dividends, and rents.

In Brazil, the topic of income distribution has gained great importance in recent years, both in the academic field and the political arena. Following remarkable economic and social changes, the structure of income distribution in Brazil has undergone significant changes. Langoni (2005) called attention to the inequality level of the Brazilian income distribution. He highlighted that a widening inequality gap exists when comparing the 1960 data with the 1970 data. Hoffmann (1973) analyzed the income distribution patterns in the 1960s and related it to minimum wage policy changes, showing that the parameter linking degree of inequality to the minimum wage was 
negative and statistically different from zero. ${ }^{4}$ They found strong evidence of an increase in the country's concentration of income and wealth in the 1970s and 1980s.

Lacerda (1994) confirmed the rising trend of income distribution in the 1980s, especially in the second half of the decade. The Brazilian indicators were quite above the values of most countries around the world (Table 1). According to Lacerda (1994), the main reason for this behavior was the high inflation that lasted almost two decades in Brazil and the successive failed attempts to stabilize macroeconomic indicators and wage policies.

Looking at the data of the twenty-first century, Hoffmann and Ney (2008) analyzed the fall in income inequality in the early years using the PNAD data from 1995 to 2006. They focused the analysis on important states of Brazil such as São Paulo, Minas Gerais, and Rio de Janeiro. Soares, Soares, Medeiros, and Osório (2006) also arrived at the same conclusion, stating that inequality in Brazil began to fall before 2006, mainly because of the decrease in shares retained by people in the highest quantiles.

One shortcoming of the PNAD survey is that income data of upper quantiles may be underestimated. Households were asked to provide their level of income. Medeiros, Souza, and Castro (2015) used income data collected by the Brazilian Federal Revenue Agency that are a more accurate source of information and combined this dataset with PNAD. They argued that earned income is underestimated at higher deciles. Hence, there is a probability that our inequality estimates calculated from PNAD may be underestimated (see also Hoffmann, 1988, and Barros, Cury, \& Ulyssea, 2007); however, we build a time series of informed income and assume that underestimation does not

Table 1. Income Inequality in Brazil and Selected Countries.

\begin{tabular}{lrc}
\hline & \multicolumn{2}{c}{ Income Retained by top 10\% } \\
\cline { 2 - 3 } Country & Share & Year \\
\hline Brazil & 53.2 & 1989 \\
Colombia & 35.8 & 1988 \\
Pakistan & 31.3 & 1985 \\
Swiss & 29.8 & 1982 \\
India & 26.7 & 1983 \\
France & 25.5 & 1979 \\
Italy & 25.3 & 1986 \\
United States & 25 & 1985 \\
Bangladesh & 24.5 & 1982 \\
Germany & 23.4 & 1984 \\
Japan & 22.4 & 1979 \\
Belgium & 21.5 & 1979 \\
Sweeden & 20.8 & 1981 \\
\hline
\end{tabular}

Source: World Bank

\footnotetext{
${ }^{4}$ Hoffmann and Kageyama (1986) analyzed the income distribution and its time evolution since the mid-1970s, when a series of indicators started to be released. The main example is the PNAD collected by IBGE, the Brazilian Institute of Geography and Statistics.
} 
change over time, which seems reasonable in Brazil. Our procedure still allows us to compare the evolution of income concentration over time. ${ }^{5}$ Figure 1 illustrates income distribution in our sample. We detail its evolution in the following.

\subsubsection{Poorest $10 \%$ household quantile}

The income share of Brazil's poorest $10 \%$ households in 2013 was $1.2 \%$ of the total income of the country. The highest value in our sample period was $1.3 \%$. This share has remained almost stable from 2003 onward. The results suggest that this quantile played a secondary role in the observed reduction of the income inequality in Brazil after the end of this sample period. Income shares rose substantially when data from 2000 is compared with those at the beginning of the sample to the early years in the 1990s. The lowest share was $0.7 \%$ in 1989 when Brazilian inflation peaked to almost $90 \%$ per month in the consumer price index.

The data for Brazilian regions are not much different from aggregated data. For the lowest $10 \%$ quantile, the southern and southeast regions have the highest income shares of $1.6 \%$ and $1.4 \%$, respectively. These regions showed considerable improvement in recent years.

In 1990 , the income shares were $0.9 \%$ and $0.8 \%$ in the southern and southeast regions, respectively, with increasing rates from the end of the 1990s. For the midwest region, the income share was $1.3 \%$ in 2013 for the poorest $10 \%$ households.

Two regions have means below the Brazilian average: the north and northeast, with $1.1 \%$ and $0.9 \%$, respectively. At the beginning of the $1990 \mathrm{~s}$, an improvement of the share of the northern region was observed, rising from $0.9 \%$ in 1990 to $1.7 \%$ in 2005 , the highest among all regions. Subsequently, the northern region started to experience a decline in income share. It is quite different for the northeast region in which the indicator remained stable from the late 1990s to the end of the sample period, and the values were below the national average.

A rising trend is apparent in the shares of the southern and southeast regions since the mid-1990s, accounting for $1.6 \%$ and $1.4 \%$, respectively. The number for these shares in 1990 were $0.9 \%$ in the south and $0.8 \%$ in the southeast. Midwest regional data also showed an improvement in income shares retained by the poorest ones probably because of better economic performance and agricultural development of the region.

The northeast continues to be the region where Brazilian poverty is most apparent. According to the PNAD data, $43.1 \%$ of the poorest Brazilians lived in the northeast region in 2013. However, there have been improvements in recent years. For example in 1977 , the northeast had $65.9 \%$ of the poorest households. One possible explanation for the change has to do with the "Real Plan", a successful macroeconomic stabilization program launched in 1994. Inflation rates dropped substantially, and the level of inflation tax collection was dramatically reduced. Since the poorest households did not have proper tools to protect their income against inflation, macroeconomic stabilization significantly helped maintain their income shares.

\footnotetext{
${ }^{5}$ Household data are protected by a banking secrecy law that restricts access to these data. The Brazilian Federal Revenue Agency, unfortunately, does not allow ample access to the academic community.
} 


\section{Dataset and Econometric Methodology}

The goal of this present study is to analyze the evolution of income distribution among households, focusing on the participation of the $1 \%$ and $10 \%$ of the richest quantiles and the $10 \%$ and $50 \%$ of the poorest quantiles for aggregated and regional data. Our sample will cover the period from 1977 to 2013 using the Brazilian aggregated and regional data (north, northeast, south, southeast, and midwest). It covers 37 years of Brazilian history on the subject. We build these data using the first released household survey in Brazil (1977) up to the most recent one.

\subsection{Dataset}

PNAD was first released in 1967 by IBGE on a quarterly basis, but with a restricted geographical coverage. This format lasted with minor changes until 1973 when its geographic coverage was expanded. At that time, PNAD became the most comprehensive survey in Brazil. During the census in 1974 and 1975, PNAD data were not collected. After 1976, the survey was reformulated and the frequency changed to annual.

The PNAD survey questionnaire continued to undergo major changes until 1979. Subsequently, the structure of the survey suffered minor changes over time. However, geographical coverage has remained unchanged until 2004. The residents of the rural northern region in Brazil were included in the survey, and minor changes in the questionnaire and indicator definitions were made in that period without compromising data compatibility.

Another drawback with the survey is that income obtained from real states and investment such as rents, interest rate, and dividends are often poorly recorded, underestimating income shares for the highest quantiles of society. This issue was raised by Hurst, Li, and Pugsley (2014).

Although the aforementioned problems persist, the PNAD survey has proved valuable in describing the trends exhibited by household income distribution well and continues to help the Brazilian government and scholars to access the results of income distribution policies among other issues.

The data for this study come from PNAD microdata from 1977 to 2013, except for the census years when there was no survey. IBGE did not collect data in 1994. To deal with this data deficiency, we performed a reconstruction of the series to fill missing data points. We opt to use unobserved component methodology. By using a statespace model adapted to the case where the sample contains missing data, we can obtain estimates of missing points. Reconstruction of the series does not change the actual values obtained from the data of PNAD but only adds estimates for missing values. ${ }^{6}$

The PNAD survey allows us to identify individuals, families, and households. We disregarded all individuals that did not answer the questions about income. The remaining data are used even if the answer of the individual was zero to the question on income level (no income at all).

Finally, all models were estimated using Oxmetrics 7.0 packages: PcGive and STAMP.

${ }^{6}$ Our results are not sensitive to those assumptions and are available upon request. 


\subsection{Econometric methodology}

\subsubsection{Markov-switching model}

Markov-switching regime models are non-linear class models of time-series analysis in which there is a probability of transition between regimes connected to the immediately preceding period. These models are very useful in modeling series that present periods with distinct behaviors. For example, one should not expect a recessionary economy to behave in the same way as an economy in a period of expansion. This non-linearity in economic series can be modeled from regime-switching models. We will use a Markovswitching autoregressive model that allows three regimes. The estimated model will have the following form:

$$
y_{t}=c_{k}+\phi_{k} y_{t-1}+\varepsilon_{1 t} \quad \text { if } \quad s_{t}=k,
$$

where $s_{t}$ takes the values $k \in\{1,2,3\}$.

We can define a set of transition probabilities between the regimes as $p_{i j}$. This probability can be defined as the probability of the regime $i$ being followed by the regime $j$. The phenomenon is governed by a non-observed Markov chain process in which the probabilities model the transition from one conditional function to another. The model estimation process depends on the construction of a likelihood function and its optimization using an algorithm similar to that suggested by Hamilton (1989). First, the likelihood function is optimized, next the filtered and smoothed probabilities are calculated, and finally, standard deviations and statistics are calculated for inference.

\subsubsection{Structural times series models}

According to Watson and Engle (1983), the use of unobservable variables in Economics is widely accepted as a useful approach to describe economic phenomena. The general idea of the structural model for time series is that the series is a sum of components, not necessarily observed, such as trend, seasonality, and cycles, wherein each component evolves according to a particular dynamic. Structural models in a state-space representation offer a very interesting approach to forecasting. One can define a state-space model as follows:

$$
\begin{array}{rlrl}
y_{t} & =Z_{t} \alpha_{t}+\varepsilon_{t} & \varepsilon_{t} \stackrel{\text { iid }}{\sim} \mathcal{N}\left(0, H_{t}\right), \\
\alpha_{t+1}=T_{t} \alpha_{t}+R_{t} \eta_{t} & \eta_{t} \stackrel{\text { iid }}{\sim} \mathcal{N}\left(0, Q_{t}\right),
\end{array}
$$

where $y_{t}$ is a vector of observations $p \times 1 ; \alpha_{t}$ is the state vector, which is unobserved and has dimension $m \times 1 ; \varepsilon_{t}$ and $\eta_{t}$ are independent error terms; $H_{t}$ and $Q_{t}$ are covariance matrices; and iid denotes independent and identically distributed. $Z_{t}, T_{t}$, and $R_{t}$ are vectors with known and estimated elements. The model estimation is conducted using the Kalman filter combined with maximum likelihood, in which the forecast errors are minimized. The Kalman filter is composed of a set of equations to estimate recursively in time the mean and conditional variance of the state vector. De Rossi and Harvey $(2009,2006)$ discuss the methods in using the state-space model to model the dynamics of different quantiles.

The estimated state-space structural model was decomposed into trend $\left(\mu_{t}\right)$ and an autoregressive component $\left(\psi_{t}\right)$. Note that (4), (5), (6), and (7) represent a restricted 
version of models (2) and (3). Thus, model configuration follows the form of the basic structural model with an autoregressive component, which can be written as follows:

$$
\begin{aligned}
y_{t} & =\mu_{t}+\psi_{t}+\varepsilon_{t} & \varepsilon_{t} \stackrel{\text { iid }}{\sim} \mathcal{N}\left(0, \sigma_{\varepsilon}^{2}\right) \\
\mu_{t+1} & =\mu_{t}+\beta_{t}+v_{t} & v_{t} \stackrel{\text { iid }}{\sim} \mathcal{N}\left(0, \sigma_{v}^{2}\right) \\
\beta_{t+1} & =\beta_{t}+\eta_{t} & \eta_{t} \stackrel{\text { iid }}{\sim} \mathcal{N}\left(0, \sigma_{\eta}^{2}\right) \\
\psi_{t+1} & =\rho \psi_{t}+\xi_{t} & \xi_{t} \stackrel{\text { iid }}{\sim} \mathcal{N}\left(0, \sigma_{\xi}^{2}\right)
\end{aligned}
$$

where $\psi_{t}$ denotes a component that has an autoregressive dynamics; $\beta_{t}$ is a component that generate a time trend; $\mu_{t}$ is denotes the level; $\varepsilon_{t}, v_{t}, \eta_{t}$, and $\xi_{t}$ denote iid variables; and $\rho$ is an autoregressive parameter.

\section{Results}

This section is divided into two parts. The first part focuses on the results obtained from Markov-switching time series models, whereas the second part focuses on the results of state-space models. We performed both exercises for the Top 1\%, Top 10\%, Bottom 10\%, and Bottom 50\% quantiles using aggregated and regional disaggregated data. The goal is to investigate whether evidence of a changing pattern exists in income distribution in Brazilian regions and when it occurred. The descriptive analysis in the previous sections suggests that there was a significant change in income distribution pattern in the first decade of 2000 toward greater equality.

\subsection{Markov-switching models}

We estimate a Markov-switching autoregressive model to understand better the dynamics of quantile income shares for Brazilian aggregated and disaggregated data. We opt to work with at most three different regimes of income shares (high, intermediate, and low). We opt to choose three regimes due to the fact that Brazilian economy had a period of high growth and moderate inflation in the 1970s, followed by a period of low growth and very high inflation in 1980s and half of 1990's. Finally, the period of 2000's had moderate growth and low inflation levels for Brazilian standard. ${ }^{7}$

The models are estimated for the Bottom 10\%, Bottom 50\%, Top 10\%, and Top $1 \%$ income share quantiles. Figures 1 and 2 show which regime is most likely to have prevailed at each point of time. Estimates of regime alternate in time and are not erratic; that is, if income share is at one regime in one period, then it tends to stay in this regime in the next period. We opt to work with three regimes because during the period covered by the sample, at least three regimes should be required: one before the 1980s when inflation was high but manageable, another during the 1980s when inflation was out of control, and finally, another regime during the 1990s and the year of the twenty-first century. Our complementary analysis using state-space models does not require setting

\footnotetext{
${ }^{7}$ Although in state space models methodology we do need to specify the number of regimes, estimate of unobserved component can provide information if a relevant change had occurred in DGP of the data. Results of section 4.2 show that the three regime hypothesis is adequate.
} 
a number of specific regimes, but the results provide evidence that corroborates this hypothesis.

\subsubsection{Brazilian data}

First, we analyze the Brazilian aggregated data. For the Bottom $10 \%$ quantile data (first graph of Figure 1), there is clear evidence of three regimes during the sample period: low, intermediate, and high-income shares. The intermediate share regime prevailed from the beginning of the sample period (1977) to the mid-1980s. This regime was followed by the low-income share regime from the mid-1980s to 1998. Subsequently, from 1998 to 2003, intermediate-income share regime prevailed again. From 2003 to the end of the sample period, the high-income share regime prevailed.

For the $50 \%$ poorest quantile, it is possible to tell a different history. The regime with the lowest mean lasts from the beginning of the sample period to 2002. From 2002 to 2006, a second regime prevailed. Subsequently, from 2006 to the end of the sample period, a third regime that is clearly a high-income share regime took place. The second regime seems to be a transition from a low- to high-income share regime. This suggests that the 1980s inflationary crisis had severe effects on the income share of the poorest households but not that severe on the $50 \%$ quantile.

Finally, for the Top $10 \%$ quantile, an intermediate regime prevailed in almost all points from the beginning of the sample period to 2002. Subsequently, a regime of low-income shares started to prevail, and a third regime associated with positive peaks of income shares occurred at the beginning of the sample period and at the end of the 1980s when the Brazilian economy was facing unprecedented inflation crisis. It is reasonable to conclude that a transition from a higher to a lower level of income share exists in around 2003 for Top 10\% quantiles.

As a stylized fact, there is clear evidence in favor of a transition toward a more equal income distribution pattern in Brazilian data. This movement started with the poorest ones in the late 1990s probably because of changes in the macroeconomic environment and became stronger during the first decade of 2000 when it was possible to observe regime changes in all quantiles.

\subsubsection{North region}

We start our analysis with the results of the $10 \%$ poorest quantile in the northern region. Clearly, we can detect three regimes. The first one is an intermediate shares regime that lasted from the 1970s to the mid-1980s. From that time to 2000, a regime of low-income share prevailed probably as a consequence of macroeconomic instability of the economy. However, from that period to the end of the sample period, two regimes alternated: one with high-income shares and the other with intermediate-income shares. This regional picture contrasts with the national one where the regime of high-income shares tended to prevail in the same period. Particularly, the high-income share regime was followed by an intermediate one in 2008 when the Brazilian growth was reduced because of the consequences of the financial crisis in the United States. After 2010, the growth of the Brazilian economy started to decrease; this is the point where intermediate regime succeeds high-income share regime. 


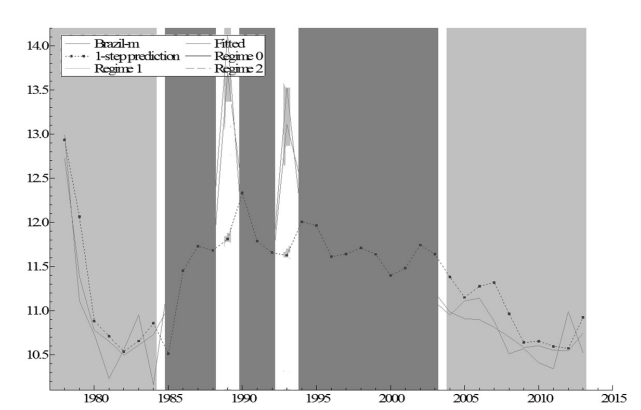

(a) Brazil

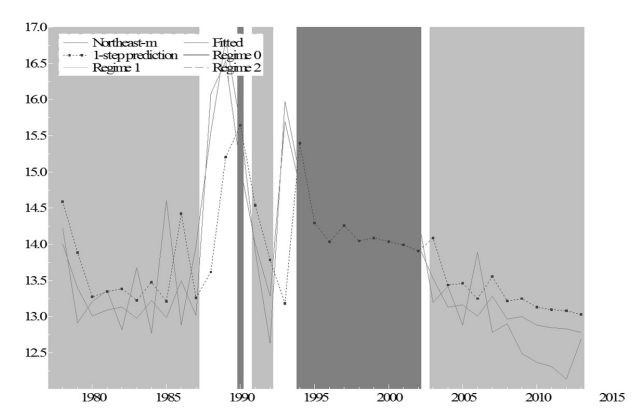

(c) Northeast

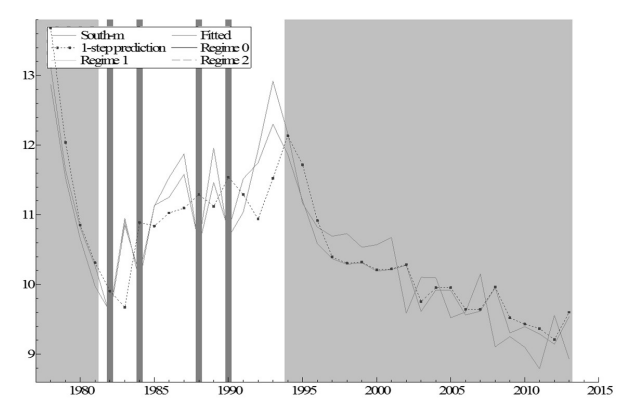

(e) South

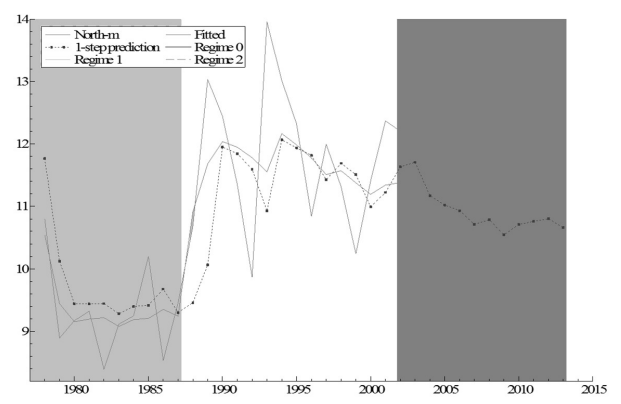

(b) North

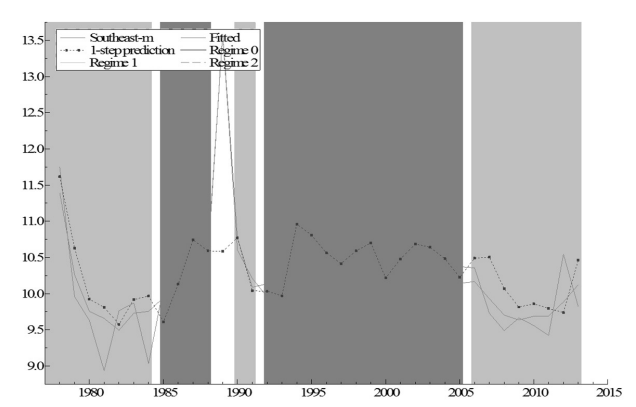

(d) Southeast

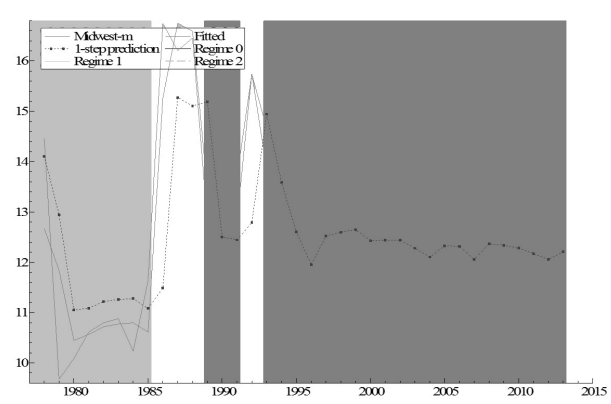

(f) Midwest

Figure 1. Smooth conditional probability using Markov-switching model for three regimes. Top $1 \%$ regime estimates. 

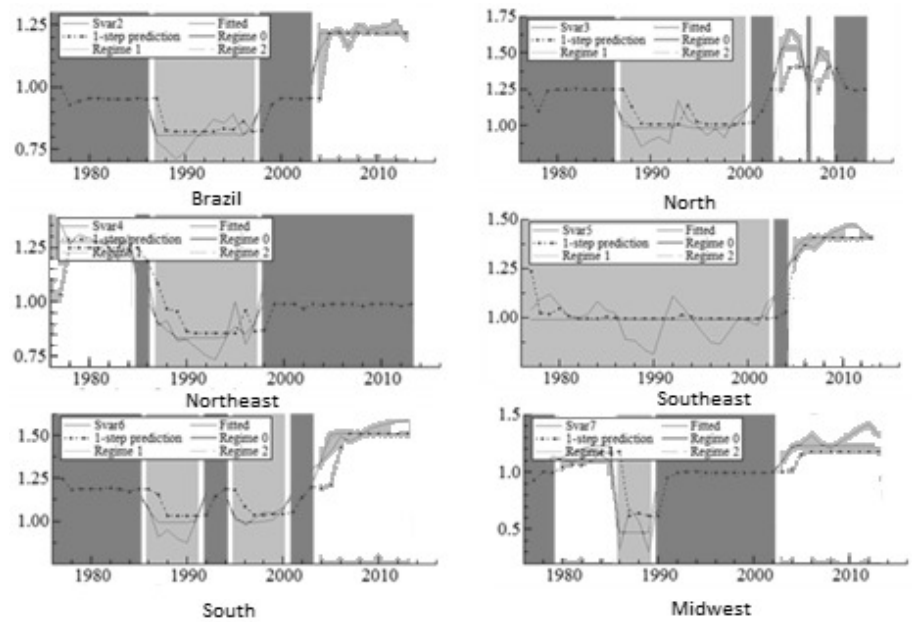

(a) Poorest $10 \%$ quantile data
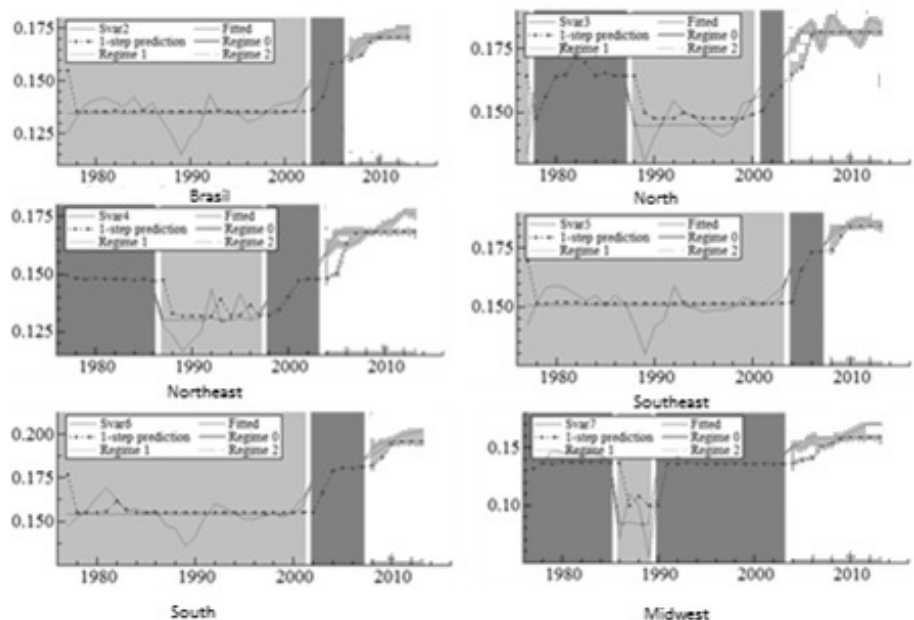

(b) Poorest $50 \%$ quantile data
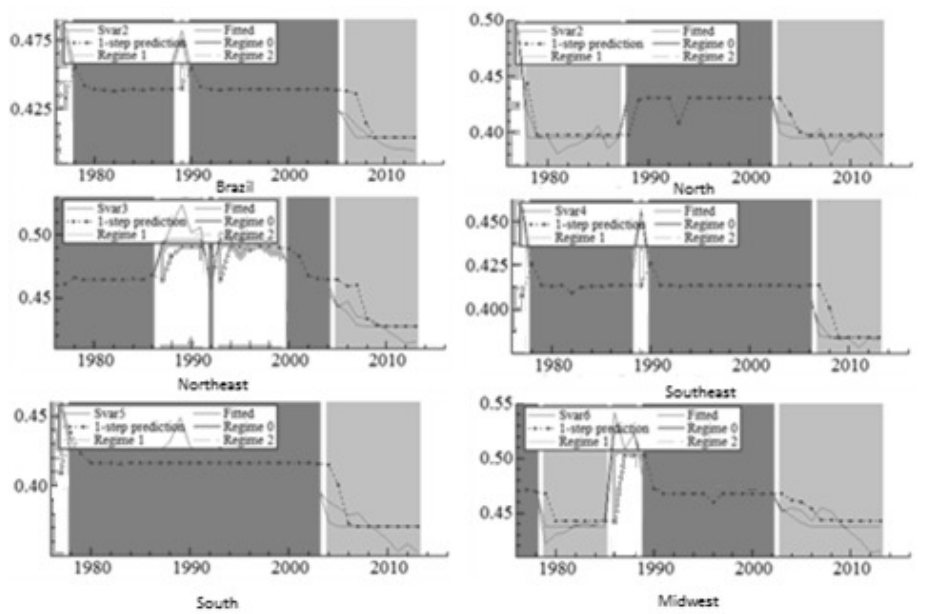

(c) Top 10\% quantile data

Figure 2. Regime probabilities obtained from a Markov-switching model for Brazil and its regions. Smooth conditional probability - Markov-switching model - 3 regimes. 
For the $50 \%$ poorest quantile, there is evidence of three distinct regimes. Bottomincome shares prevailed in the late 1980 s to 2002 . Then, a transition to intermediateincome shares occurred. Finally, from 2004 to the end of the sample period, a regime of high-income shares tended to prevail. For the Top $10 \%$ quantile, two regimes prevailed in almost all points. The first one is a high-income share regime prevailing from the mid-1980s to 2002, and the second is a low-income share regime that prevailed from 2002 to the end of the sample period.

\subsubsection{Northeast region}

Now, we look at the results of the northeast region. The pattern of income shares for the $10 \%$ poorest contrasts with the aggregated Brazilian results for the same group. The best period when income shares prevailed is at the beginning of the sample period to the mid-1980s. Then, a regime of low-income share prevailed up to 1998. Subsequently, from that period to the end of the sample period, a regime of intermediate-income shares started to prevail. The conclusion is that the 1980s macroeconomic crisis could have caused a drop in this income share quantile and that no full recovery exists until the end of our dataset.

The picture for the $50 \%$ poorest quantile differs from aggregated data. The income shares during the 1980s macroeconomic instability were negatively affected, but there was a full recovery at the end of the 1990s and an improvement from 2002 to the end of the sample period. The transition to a better position seems to have started earlier than national data for this quantile.

\subsubsection{Midwest region}

The Midwest region in Brazil has become one of the most important regions for agricultural production, particularly those related to exports. Our estimates for the Low $10 \%$ suggest the existence of three regimes. The regime of high-income shares prevailed in the late 1970s and early 1980s and after 2002. In the late 1980s, a regime of low-income shares prevailed, which was followed by an intermediate-income share regime. This regime was then followed by a high-income share regime that prevailed until the end of the sample period. This regime cannot be considered a new one because it had already prevailed in the 1980s.

For the $50 \%$ poorest quantile, a regime of intermediate-income shares prevailed in most of the period from the beginning of the sample period to 2002. Only during the late 1980s was a regime of low-income shares active. Finally, from 2002 to the end of the sample period, a regime of high shares started to prevail.

For the Top 10\%, low- and intermediate-income share regimes prevailed in most of the sample period. In the late 1980s, a regime of high-income shares had prevailed. At the end of the sample period, a regime of low-income shares seemed to be prevailing but it cannot be seen as a new regime because it had also prevailed in the 1980s.

\subsubsection{South region}

For the data in the South region, there is a clear pattern indicating new movement from 2002 to the end of the sample period. A regime of high-income shares prevailed for the Bottom $10 \%$ and $50 \%$ poorest quantiles, whereas a regime of low-income share 
prevailed for the Top $10 \%$. In the late 1980s, the low-income share regime seemed to have prevailed for the poorest quantiles.

\subsubsection{Southeast region}

The southeast region in Brazil is the most developed region in many aspects. The income distribution pattern in the southeast region contrasts in one aspect from that in other regions. There is no evidence of a low-income share regime during the 1980s in both poorest quantiles. From 2000, there is a transition toward a high-income share regime in these quantiles. Finally, in the Top $10 \%$ quantile, two regimes prevailed most of the time. From 2000 to the end of the sample period, a regime of low share prevailed, whereas in the rest of the sample except a few years in the late 1970s and late 1980s, a regime of intermediate shares was observed. Finally, some peaks in the share were observed in the late 1970 s and 1980s.

\subsection{Multivariate structural time series model}

We also estimate a local linear trend state-space multivariate time-series model with an autoregressive stationary component for Brazilian regional data ${ }^{8}$ as described in equations (4)-(7). The goal of this method is to identify a statistically significant local trend and change in the level component of data quantile. The model structure allows the trend to be time variant; that is, it allows different values for the trend in each period. This methodology is important to help us identify different patterns over the forty years sample period. Trend and level components evolve smoothly in a state-space framework, whereas in Markov-switching framework regimes, change is abrupt. The methodology also allows us to easily tackle the missing values in the sample.

\subsubsection{Brazilian data}

Figure 3 shows estimates for all components of the state-space model for the Top $1 \%$, Top 10\%, Bottom 50\%, and Bottom 10\% Brazilian income shares. All components are plotted with proper error bands. If at time $t$ the lower bound of the band is larger than all previous values of the upper bound of the band up to time $t$, it is possible to state that the level has reached a peak at time $t$. If at time $t$ the upper bound is smaller than all previous values of the lower bound of the band up to time $t$, it is possible to state that the level has reached a trough.

The first set (row) of graphs in Figure 3 show the time evolution of level component estimates. It is possible to conclude from these graphs that Bottom 10\% and Bottom $50 \%$ started to reach a sequence of peak values around 2002. The level component remained statistically above the values that had prevailed until 2002. This suggests that there is a significant improvement in the shares of these quantiles in the Brazilian income distribution. Although some changes seemed to occur in the Top 1\% quantile, there is no evidence of a statistically significant difference among the periods. In Top 10\% a statically significant drop occurred in the middle of 1990s. Major changes in income distribution pattern seems to be related to the change in lower quantiles, whereas income

\footnotetext{
${ }^{8}$ We only report results for Brazil and not regions to save space. Results can be obtained in Supplementary Material document available upon request.
} 

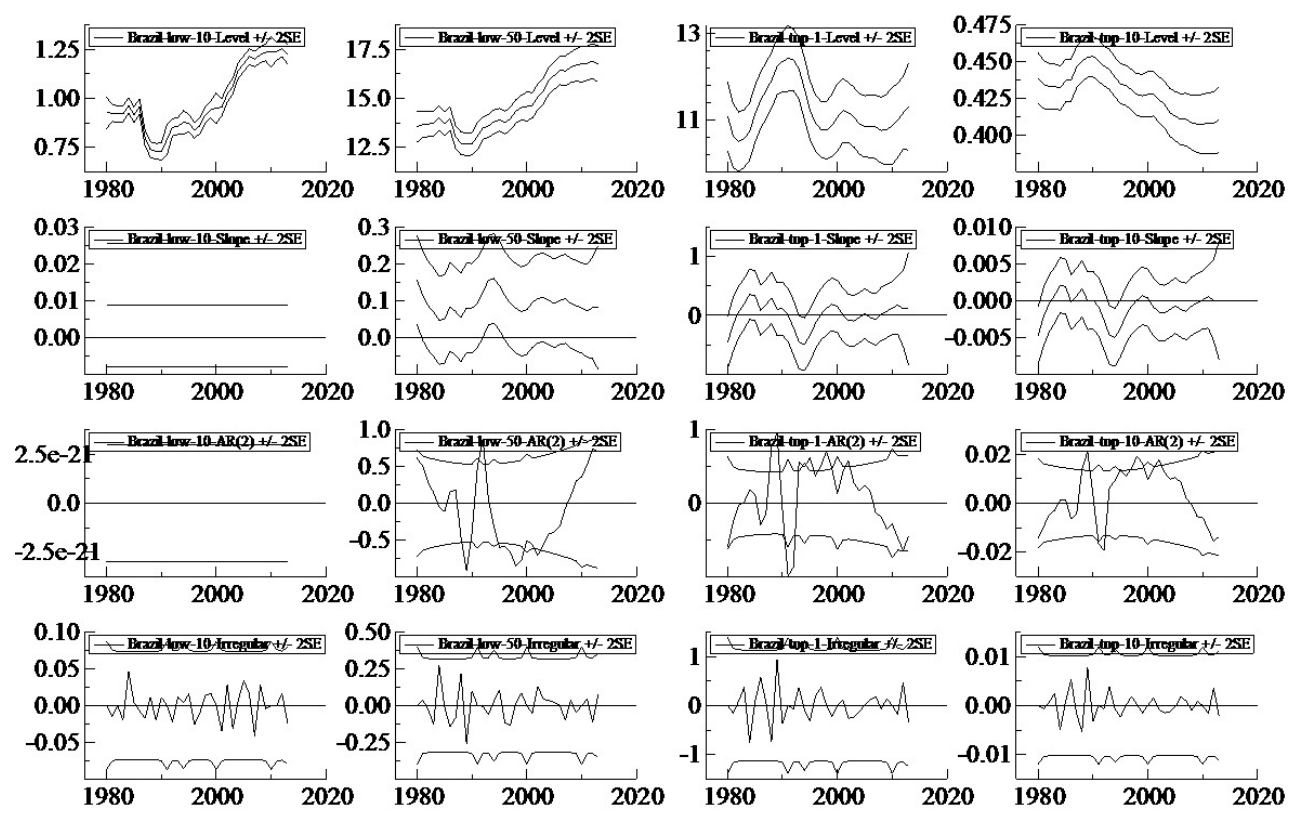

Figure 3. State-space model components for Brazil: Top 1\%, Top 10\%, Bottom 50\%, and Bottom 10\% income shares.

shares of Top 1\% quantile remained stable. Excepting Top $1 \%$ level, it is possible to conclude that at least two different regimes prevailed in all shares. In Bottom $10 \%$ and Bottom $50 \%$ evidence of three different regime seems to be more adequate.

An inspection of autoregressive component estimates $\left(\psi_{t}\right)$ suggests that a fall and recovery event took place in 1989 and 1990 at the Bottom 50\%, Top 1\%, and Top 10\% quantiles. These movements are closely related to the macroeconomic instability of the Brazilian economy at that time. The highest level of inflation in Brazilian history occurred in this year. A fall in the income share quantile is observed in 1989, whereas an opposite movement was observed in top quantiles. Moreover, the component level of the Bottom 10\% quantile reached its lowest level in 1989, and it can be classified as a trough. Recovery was slower than in other quantiles.

Finally, local trend $\left(\beta_{t}\right)$ component seems to be statistically insignificant for virtually all the sample except in about 1994 when the Brazilian government managed to implement a successful macroeconomic stabilization plan.

In summary, the national picture suggests that a statistically significant movement toward a more equal income distribution patterns at unprecedented levels started about the early 2000s, and macroeconomic instability at the end of the 1980s had a deleterious effect on income distribution.

\section{Conclusion}

The discussion on income inequality in Brazil has grown in the last decade, mainly because of changes in the economic, political, and social environment over the past 40 years. In the 1970s, the Brazilian economy faced a period of economic prosperity 
with many people evolving to middle-class standards. The second-round increases in oil prices in the late 1970s had a decisively negative impact on the Brazilian economic growth. In the 1980s, the Brazilian economy faced economic downturn, hyperinflation, and bailouts.

This paper analyzes the evolution of household income inequality in Brazil using aggregated and regional data from 1977 to 2013. The Brazilian PNAD data are used, and four income share quantiles are investigated, namely the Top $1 \%$, Top $10 \%$, Bottom $10 \%$, and Bottom 50\%.

Our results can be stated in two dimensions. Allowing for three different regimes, our estimations suggest that for individuals belonging to the Top $1 \%$ and $10 \%$ income share, a reduction can be observed in their shares in Brazil and most regions from the first decade of the twentieth century onward. This is more pronounced for the Top 10\%. An opposite movement in terms of increase in share participation is observed for the poorest individuals (Bottom $10 \%$ and $50 \%$ ), which is more pronounced for Bottom $50 \%$. However, for those on the lowest quantiles, we observe an improvement in their shares before 2000, suggesting a previous improvement in the income of those at the bottom before decreasing income participation of those at the very top. That phenomenon seems to take longer in northeast and north regions; that is, an increase in the participation shares for the lowest quantiles is only observed after 2000 . The second dimension is the result concerning the multivariate structural time-series model that allows us to decompose for transitory versus permanent movements on the series of income participation for the Top 1\%, Top 10\%, Bottom 10\%, and Bottom $50 \%$ and their statistical significance. For those at the Top 1\% quantile, we cannot reject the null hypothesis that there is no trend in any period and there is no detectable peak or trough for Brazil and most regions. However, for those at the bottom, we observe successive improvements for Brazil and most regions reaching successive peaks of income shares beginning 2000s onward.

The results also suggest not only that high inflation has produced a large income inequality in Brazil but also a large improvement has occurred after inflation was controlled. This was more pronounced after 2000. Minimum wage policy and social programs seem to have improved the income distribution after 2002. Kuznets and Jenks (1953) argued that income inequality first rises with economic development where concentrated sectors push for development but then decreases as workers join the highpaying sectors of the economy. Our data show that this may not be the cause of the increase in income inequality in the 1980s, a recession period. Furthermore, we observe a decrease in income concentration at the end of the 1990s, a growth-recovery period with much lower inflation.

\section{References}

Alvaredo, F., Atkinson, A. B., Piketty, T., \& Saez, E. (2013). The top 1 percent in international and historical perspective. Journal of Economic Perspectives, 27(3), 3-20.

http://dx.doi.org/10.1257/jep.27.3.3

Atkinson, A. B. (2005). Top incomes in the UK over the 20th century. Journal of the Royal Statistical Society: Series A (Statistics in Society), 168(2), 325-343. https://www.jstor.org/ stable/3559965 
Atkinson, A. B., \& Piketty, T. (Eds.). (2007). Top incomes over the twentieth century: A contrast between continental european and English-speaking countries. Cambridge University Press.

Atkinson, A. B., \& Piketty, T. (2010). Top incomes: A global perspective. Oxford University Press.

Bai, J., \& Perron, P. (1998). Estimating and testing linear models with multiple structural changes. Econometrica, 66(1), 47-78. https://www.jstor.org/stable/2998540

Bai, J., \& Perron, P. (2003). Computation and analysis of multiple structural change models. Journal of Applied Econometrics, 18(1), 1-22. https://www.jstor.org/stable/30035185

Barros, R. P. d., Cury, S., \& Ulyssea, G. (2007). A desigualdade de renda no Brasil encontra-se subestimada? Uma análise comparativa com base na PNAD, na POF e nas Contas Nacionais (Texto para Discussão). Rio de Janeiro: Instituto de Pesquisa Econômica Aplicada (Ipea). http://www.ipea.gov.br/portal/images/stories/PDFs/TDs/td_1263.pdf

Blinder, A. S., \& Esaki, H. Y. (1978). Macroeconomic activity and income distribution in the postwar United States. The Review of Economics and Statistics, 60(4), 604-609. https:// www.jstor.org/stable/1924254

Cline, W. R. (1995). International debt reexamined (No. 46). Peterson Institute for International Economics. https://cup.columbia.edu/book/a/9780881320831

De Rossi, G., \& Harvey, A. (2009). Quantiles, expectiles and splines. Journal of Econometrics, 152(2), 179-185. http://dx.doi.org/10.1016/j.jeconom.2009.01.001

De Rossi, G., \& Harvey, A. C. (2006). Time-varying quantiles. Retrieved July 12th, 2019, from http://www.princeton.edu/ erp/Econometrics/Old\%20Pdfs/harvey.pdf

Hamilton, J.D. (1989). A new approach to the economic analysis of nonstationary time series and the business cycle. Econometrica, 57(2), 357-484. https://www.jstor.org/stable/1912559

Harvey, A. C. (1990). Forecasting, structural time series models and the Kalman filter. Cambridge University Press.

Hoffmann, R. (1973). Considerações sobre a evolução recente da distribuição da renda no Brasil. Revista de Administração de Empresas, 13(4), 7-17. http://dx.doi.org/10.1590/S0034-75901973000400001

Hoffmann, R. (1988). A subdeclaração dos rendimentos. São Paulo em Perspectiva, 2(1), $50-54$.

Hoffmann, R., \& Kageyama, A. A. (1986). Distribuição da renda no Brasil, entre famílias e entre pessoas, em 1970 e 1980. Estudos Econômicos, 16(1), 25-51. https://www.revistas.usp.br/ ee/article/download/157261/152643

Hoffmann, R., \& Ney, M. G. (2008). A recente queda da desigualdade de renda no Brasil: Análise de dados da PNAD, do Censo Demográfico e das Contas Nacionais. Econômica, 10(1), 7-39. http://repositorio.ipea.gov.br/handle/11058/1439

Hurst, E., Li, G., \& Pugsley, B. (2014). Are household surveys like tax forms? Evidence from income underreporting of the self-employed. Review of Economics and Statistics, 96(1), 19-33. http://dx.doi.org/10.1162/REST_a_00363

Kuznets, S., \& Jenks, E. (1953). Shares of upper income groups in income and savings. National Bureau of Economic Research (NBER). https://www.nber.org/books/kuzn53-1

Lacerda, A. C. (1994). Distribuição de renda no Brasil nos anos 80. Revista de Economia Política, 14(4), 134-140. http://www.rep.org.br/pdf/55-11.pdf

Lampman, R. J. (1962). The share of top wealth-holders in national wealth, 1922-56. National Bureau of Economic Research (NBER). https://www.nber.org/books/lamp62-1 
Langoni, C. G. (2005). Distribuição da renda e desenvolvimento econômico do Brasil. FGV Editora.

Maddala, G. S., \& Kim, I.-M. (1998). Unit roots, cointegration, and structural change. Cambridge University Press.

Medeiros, M., Souza, P. H. G. F., \& Castro, F. A. d. (2015). A estabilidade da desigualdade de renda no Brasil, 2006 a 2012: Estimativa com dados do imposto de renda e pesquisas domiciliares. Ciência e Saúde Coletiva, 20(4), 971-986. http://dx.doi.org/10.1590/1413-81232015204.00362014

Pesaran, M. H. (2015). Time series and panel data econometrics. Oxford University Press.

Piketty, T. (2003). Income inequality in France, 1901-1998. Journal of Political Economy, 111(5), 1004-1042. http://dx.doi.org/10.1086/376955

Piketty, T. (2010). On the long run evolution of inheritance: France 1820-2050 (Discussion Paper No. 7854). CEPR. https://cepr.org/active/publications/discussion_papers/dp.php ?dpno $=7854$

Piketty, T. (2014). Capital in the twenty-first century. Harvard University Press.

Piketty, T., \& Saez, E. (2006, January). The evolution of top incomes: A historical and international perspective (Working Paper No. 11955). National Bureau of Economic Research (NBER). http://dx.doi.org/10.3386/w11955

Piketty, T., \& Saez, E. (2014). Inequality in the long run. Science, 344(6186), 838-843. http://dx.doi.org/10.1126/science.1251936

Raj, B., \& Slottje, D. J. (1994). The trend behavior of alternative income inequality measures in the United States from 1947-1990 and the structural break. Journal of Business \& Economic Statistics, 12(4), 479-487. http://dx.doi.org/10.1080/07350015.1994.10524570

Roine, J., \& Waldenström, D. (2011). Common trends and shocks to top incomes: A structural breaks approach. Review of Economics and Statistics, 93(3), 832-846. http://dx.doi.org/10.1162/REST_a_00112

Soares, F. V., Soares, S., Medeiros, M., \& Osório, R. G. (2006, October). Programas de transferência de renda no Brasil: Impactos sobre a desigualdade (Texto para Discussão No. 1228). Instituto de Pesquisa Econômica Aplicada (Ipea). http://repositorio.ipea.gov.br/ bitstream/11058/1905/1/TD_1228.pdf

Soltow, L. (1991). Distribution of wealth and income in the United States in 1798. University of Pittsburgh Press. http://dx.doi.org/10.2307/2597518

Tachibanaki, T. (2006). Confronting income inequality in Japan: A comparative analysis of causes, consequences, and reform. MIT Press Books.

Watson, M. W., \& Engle, R. F. (1983). Alternative algorithms for the estimation of dynamic factor, mimic and varying coefficient regression models. Journal of Econometrics, 23(3), 385-400. http://dx.doi.org/10.1016/0304-4076(83)90066-0

Zivot, E., \& Andrews, D. W. (1992). Further evidence on the Great Crash, the Oil-Price Shock, and the unit-root hypothesis. Journal of Business \& Economic Statistics, 10(3), 251-270. http://dx.doi.org/10.1198/073500102753410372 